\title{
Activating social strategies: Face-to-face interaction in technology- mediated citizen science
}

\section{Francesco Cappa ${ }^{a, b, c}$, Jeffrey Laut ${ }^{a}$, Oded Nov ${ }^{d}$, Luca Giustiniano ${ }^{b *}$, Maurizio Porfiri ${ }^{a *}$}

a New York University, Tandon School of Engineering, Department of Mechanical and Aerospace Engineering, Brooklyn, 11201 New York, USA

b LUISS Guido Carli University, Department of Business and Management, 00197 Rome, Italy

c Tuscia University, Department of Economy and Business, 01100 Viterbo, Italy

$d$ New York University, Tandon School of Engineering, Department of Technology Management, Brooklyn, 11201 New York, USA

* Corresponding author. Telephone number: +1 646997 3681; E-mail address: mporfiri@nyu.edu

* Corresponding author. Telephone number: +39068522 5946; E-mail address: lgiusti@luiss.it

\begin{abstract}
The use of crowds in research activities by public and private organizations is growing under different forms. Citizen science is a popular means of engaging the general public in research activities led by professional scientists. By involving a large number of amateur scientists, citizen science enables distributed data collection and analysis on a scale that would be otherwise difficult and costly to achieve. While advancements in information technology in the past few decades have fostered the growth of citizen science through online participation, several projects continue to fail due to limited participation. Such web-based projects may isolate the citizen scientists from the researchers. By adopting the perspective of social strategy, we investigate within a measure-manipulate-measure experiment if motivations to participate in a citizen science project can be positively influenced by a face-to-face interaction with the scientists leading the project. Such an interaction provides the participants with the possibility of asking questions on the spot and obtaining a detailed explanation of the citizen science project, its scientific merit, and environmental relevance. Social and cultural factors that moderate the effect brought about by face-to-face interactions on the motivations are also dissected and analyzed. Our findings provide an exploratory insight into a means for motivating crowds to participate in online environmental monitoring projects, also offering possible selection criteria of target audience.
\end{abstract}

Keywords

Citizen science, crowd involvement, environmental monitoring, face-to-face interaction, motivations, social strategies.

1 of 30 


\section{Introduction}

Participants external to the boundaries of an organization are becoming increasingly important in the production and sharing of knowledge (Chesbrough, 2006; Felin and Zenger, 2011; O'Mahony and Ferraro, 2007; Sauermann and Franzoni, 2015). These participants are at the core of "crowd sourcing" which can be defined as "finding what you need not internally or from traditional vendors, but from people loosely affiliated through the Internet" (Seltzer and Mahmoudi, 2013). Crowd sourcing has also reached to the domain of scientific activities, leading to the involvement of contributors, external to the boundaries of an organization, in the production of the scientific research (Tushman et al., 2012), alongside professional scientists in public and private projects (Boudreau and Lakhani, 2013, 2009; Franzoni and Sauermann, 2014). Organizations increasingly have access to data on a massive scale, but are often in short supply of an efficient means for their gathering and examination, pushing the need to seek external support for improving research output (Garcia Martinez and Walton, 2014).

Among various forms of crowd participation, citizen science is a framework for involving volunteers from the general public, "citizen scientists", in scientific investigations, data collection, and interpretation of results (Dickinson et al., 2012; Paul et al., 2014; Riesch et al., 2013; Wiggins and Crowston, 2010). Citizen science projects can be started by citizens as an answer to local needs in a bottom-up, or community-driven, process, or they can be started and conducted by professional researchers in a top-down, or scientists-driven approach, where citizens are asked to contribute to particular tasks (Danielsen et al., 2009; Devictor et al., 2010; Newman et al., 2012). The former typology is more common but mainly focused on local issues and participation, while the latter typology is more amenable for scaling up and engaging a greater amount of citizens and researchers (Wiggins and Crowston, 2011). Toward increasing participation in citizen science projects, recent advances in information technology have been leveraged to facilitate collaboration and overcome geographical (Franzoni and Sauermann, 2014; Gouveia et al., 2004; Laut et al., 2016), social (Gouveia et al., 2004), and physical barriers (Laut et al., 2015).

This so-called technology-mediated citizen science can be implemented on a large scale, producing high quality data and unexpected scientific insight (Fore et al., 2001). Citizen science brings many benefits to both researchers and citizens alike. For example, it provides more eyes and ideas to the project (Haklay, 2013; Raddick et al., 2009), promotes environmental awareness (Gouveia et al., 2004; Paul et al., 2014), reduces the overall costs of scientific research (Conrad and Hilchey, 2011; Nov et al., 2014), enhances literacy as citizens become more knowledgeable about science and the process of 2 of 30 
scientific inquiry (Bonney et al., 2009; Trumbull et al., 2000), mobilizes citizens and connects them with scientists (Bonney and LaBranche, 2004), creates a stimulating and enjoyable experience (Raddick et al., 2009), and enacts social practices for public good (MacIntyre, 1984; Von Krogh et al., 2012).

Among technology-mediated citizen science projects, environmental monitoring is particularly suitable for its need of large-scale data collection and analysis (Lovett et al., 2007; Silvertown, 2009). Citizens could be involved in such distributed environmental monitoring and data analysis activities without any particular background knowledge required (Dickinson et al., 2010; Jordan et al., 2008). Well-known examples of citizen science projects include eBird, which seeks to document the abundance of bird species and address conservation problems (Sullivan et al., 2014) and Smart Citizens, where mobile devices are used to collect environmental data (Capdevila and Zarlenga, 2015). Users do not need to be highly trained, or even have any formal education at all (Stevens et al., 2014), as citizen science projects can also lend the opportunity of increasing environmental learning (Becker et al., 2013; Hasenfratz et al., 2012). For citizen science-based environmental activities, the larger is the amount of data collected and analyzed, the stronger are the conclusions that can be drawn (Fairweather, 1991). The continuous involvement of motivated volunteers is still a crucial issue in citizen science online projects, as the majority of online communities tend to fail and disappear (Dahlander and Piezunka, 2014; Iriberri and Leroy, 2009; Langner and Seidel, 2014; Ling et al., 2005). In this research, we empirically tested a novel approach to increase motivations to participate in a technology mediated citizen science project for environmental monitoring.

The understanding of motivations underlying information and resource sharing in online platforms has attracted substantial scholarly attention in recent years (Feller, 2005; Franzoni and Sauermann, 2014; Giustiniano and Bolici, 2012; Hertel et al., 2003; Lakhani and Wolf, 2003; Lakhani and Von Hippel, 2003; Preece and Shneiderman, 2009; Roberts et al., 2006; Schroer and Hertel, 2009; Seidel and Langner, 2015). Recent studies have sought to elucidate the factors that bring people to participate (Brabham, 2010; Oreg and Nov, 2008), as well as motivational determinants of the quality and quantity of contributions (Nov et al., 2014). Yet, the design of effective approaches to increase motivations to participate in citizen science is still a rather untapped field of study (Franzoni and Sauermann, 2014). People participate in citizen science projects voluntarily beyond immediate rewards (Von Krogh et al., 2012), due to different motivations as follows. They may be motivated by collective motives related to the importance they ascribe to the collective problem targeted by the project (Holohan and Garg, 2005; 3 of 30 
Klandermans, 1996; Nov et al., 2014). There are also norm-based motives driving their participation, as they may care about the reaction of family and friends (Klandermans, 1996; Nov et al., 2014). A portion of their efforts may also be related to a reward expected through a personal reputation enhancement (Holohan and Garg, 2005; Klandermans, 1996, 2003; Nov et al., 2014). In addition, participation could be due to the social interaction needs of contributors, as they may look forward to creating new relationships (Klandermans, 2003). Social strategies that promote project involvement by offering unconventional social connections, such as those with professional researchers posited here, are an emerging area of study (Piskorski, 2011). Moreover, people may want to participate because they identify with the scientific aim of the group (Holohan and Garg, 2005; Toch, 2013). Finally, participation may be due to individual interests, either enjoyment or information seeking and learning about the topic (Deci and Ryan, 2000; Holohan and Garg, 2005; Nov et al., 2014; Raddick et al., 2010).

This work proposes a novel approach for increasing users' motivations to participate in technologymediated citizen science projects, analyzing both the individual motivational drivers and the overall motivation computed as their sum. In greater detail, we empirically study the impact of a face-to-face interaction with professional researchers on participants' motivations to contribute to a citizen science project. We follow Piskorski's suggestion to experience active face-to-face interactions, in this case between researchers and citizens, beyond online participation toward fostering citizen involvement (Piskorski, 2014). The Brooklyn Atlantis citizen science project is used as a case study [http://www.brooklynatlantis.poly.edu/], where contributors connected through the web help researchers in the analysis of water quality data collected by an aquatic robot in a polluted canal located in Brooklyn, New York USA. Through the help of citizen scientists, the project enables mapping and studying the canal environment. Brooklyn Atlantis has a large number of registered users on the webbased platform. However, like many other citizen science projects, most users contribute very little, with a handful of devoted users making the majority of contributions (Franzoni and Sauermann, 2014). Furthermore, it is not uncommon for users to log-in and contribute only one time. In light of this, it is important to gain an understanding of how to continuously recruit new citizen scientists, and how to keep them motivated to regularly contribute to the project.

The potential benefits of interactions with researchers have already been demonstrated in humanmachine settings and virtual brand communities (Baker et al., 2001; Wu and Fang, 2010). In the former scenario, individual behavior has been found to be positively influenced by an interaction with professionals. In particular, from an experimental study conducted on 80 participants, the authors 4 of 30 
showed that motivations of physical therapy patients to reach set milestones increased upon involvement in goal setting with the professional therapists (Baker et al., 2001). In the latter scenario, face-to-face interactions are relied upon for a better understanding of relevant issues (Wu and Fang, 2010). Thus, a positive effect on citizen scientists' motivations is expected to be observed from the face-to-face interaction proposed herein. Such an experience offers participants the opportunity to become aware of the project details as well as ask questions and receive detailed information on the spot.

The interaction with the researchers may foster a feeling of playing a more central role in the project, thereby causing an increased sense of commitment that could maintain participants motivated to volunteer (Ryan et al., 2001). Face-to-face interactions also offer benefits with respect to knowledge transfer, whereby co-location is central for knowledge dissemination (Song et al., 2007). Knowledge has explicit and tacit components, and the latter are bolstered by face-to-face interactions (Zhao et al., 2004) which convey information beyond the literal message through multiple cues that are difficult to incorporate in online interactions, including body language, facial expression, and tone of voice (Koskinen and Vanharanta, 2002). Our approach could potentially be extended to online interactions, where we could envision online participants to interact with researchers from their computers. However, face-to-face interactions are important to establish mutual acceptance (Goffman, 2005) and maintain supportive relationships (Andrews, 2002), thus participants may be reluctant to interact online with people they have not met face-to face. Therefore, the first research question we seek to address with this study is: Does face-to-face interaction positively affect motivations to participate in technology-mediated citizen science? Within this question, we seek to test two hypotheses:

- Hypothesis la: each motivation to contribute to citizen science will be positively affected by the face-to-face interaction;

- Hypothesis $1 b$ : the overall motivation to contribute to citizen science, computed as the sum of survey scores for each motivation, will increase after the face-to-face interaction.

In addition, we analyze if social and cultural factors, which have been found to affect personal motivations (Deci and Ryan, 2000), moderate the effects brought by the face-to-face interaction on participants' motivations. As citizen science projects target all citizens without regard to age and previous knowledge (Dickinson et al., 2010; Raddick et al., 2010), it is interesting to investigate if these factors could moderate motivations to participate and the effect brought about by face-to-face 5 of 30 
interaction. The inclusion of age as a moderating variable rests on the demonstrated role of age on environmental awareness and concern, which is the basis of many citizen science projects (Aminrad et al., 2011; Wiernik et al., 2013). By including previous research experience as a moderating variable, we seek to assess if participants with previous exposure to research collaboration and/or scientific cooperation with scholar and scientists, through a $\mathrm{PhD}$ degree, will be less positively impacted by the interaction with the researchers. In the literature, a similar result was evidenced by Knutson et al. (2010), where motivations of students without a significant research history were found to be more positively affected by a research-based learning project compared to those with a prior research experience. In particular, the second research question we seek to address is: Do age and previous research experience have moderating effects on the impact of face-to-face interaction? Specifically, we seek to test the following hypotheses:

- Hypothesis $2 a$ : older participants will have a more positive reaction to face-to-face interaction;

- Hypothesis $2 b$ : participants with research experience will have a less positive reaction to the face-to-face interaction.

\section{Mehods}

\subsection{Brooklyn Atlantis case study: hardware and software}

Brooklyn Atlantis is a top-down citizen science project focused on environmental monitoring of the Gowanus Canal in Brooklyn, NY, one of the country's most polluted waterways. The canal, which was declared a superfund site in 2010 by the United States Environmental Protection Agency, is on the National Priority List for remedial investigations (https://epa.gov/region2/superfund/npl/gowanus), has a history of environmental abuse and neglect, primarily due to the industry that once surrounded it. Although much of the industrial pollution has ceased, raw sewage runoff, combined with the canal's naturally stagnant water, continues to be a source of concern. Despite its polluted state, the canal hosts a variety of wildlife. The aim of this superfund project is to develop and act on a plan for addressing the contamination and the inlets points of polluted water by collecting water quality data and images of the entire canal.

Brooklyn Atlantis assesses the water quality and wildlife presence in addition to informing the community of the state of the canal. By involving citizen scientists, the project is also able to increase the scientific literacy and awareness about water quality and wildlife issues in the canal. The Brooklyn 
Atlantis system consists of an aquatic robotic vehicle and a website. The aquatic robot (Figure 1(a)) travels throughout the canal, collecting water quality and image data. While researchers can analyze water quality data, consisting of $\mathrm{pH}$, conductivity, dissolved oxygen, and temperature, the analysis of image data collected can be extremely time intensive. During each deployment, the aquatic robot can collect about thousands of images, all of which need to be manually viewed to flag any notable content, such as wildlife or debris. Citizen scientists can collaborate with the researchers by viewing the images and tagging them via the online interface (Figure 1(b)).
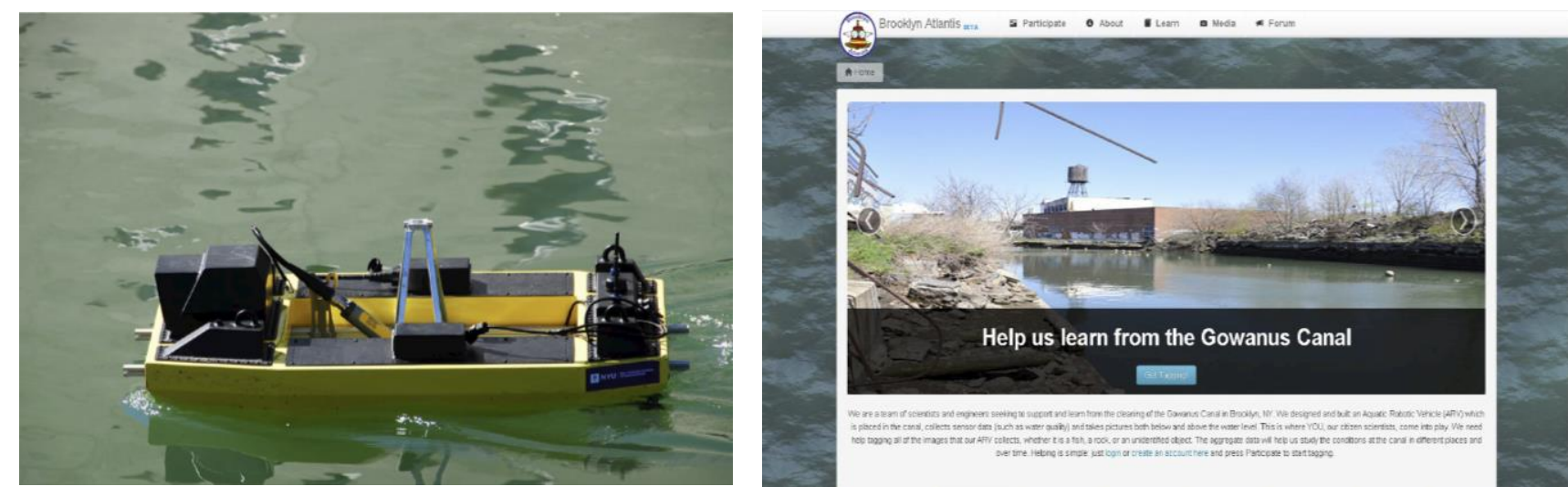

Figure 1 - Elements of the Brooklyn Atlantis citizen science project: (a) Aquatic robot to collect pictures; and (b) web-based platform to analyze data of the Brooklyn Atlantis project.

\subsection{Research design}

A measure-manipulate-measure experiment is performed, where the outcomes of surveys, a method already used in literature to evaluate motivations (Bergendahl et al., 2015; Gilson et al., 2012), gauging the motivation that bring volunteers to participate (Deci and Ryan, 2000; Klandermans, 1996, 2003; Nov et al., 2014; Toch, 2013) are compared to understand the effects of the face-to-face interaction with the researchers. The purpose of this study is to empirically provide evidence that face-to-face interactions are a way to improve the motivation to contribute in citizen science projects (hypothesis 1), and for whom it will be more effective (hypothesis 2).

Towards addressing these aims, the scores of participants' motivations from the two 1-7 Likert scaled surveys, filled in before and after the experience with the scientists, are compared to assess the effects brought by the face-to-face interaction with the researchers. To test Hypothesis 1a, the overall motivation, computed as the sum of survey marks for each motivation, is compared before and after interaction. To test Hypothesis 1b, each single motivational driver is compared before and after the experience with the researchers. Hypotheses $2 \mathrm{a}$ and $2 \mathrm{~b}$ are tested by ascertaining if age and previous 
research experience moderate the main effect reported in Hypothesis 1a, through the model depicted in Figure 2.

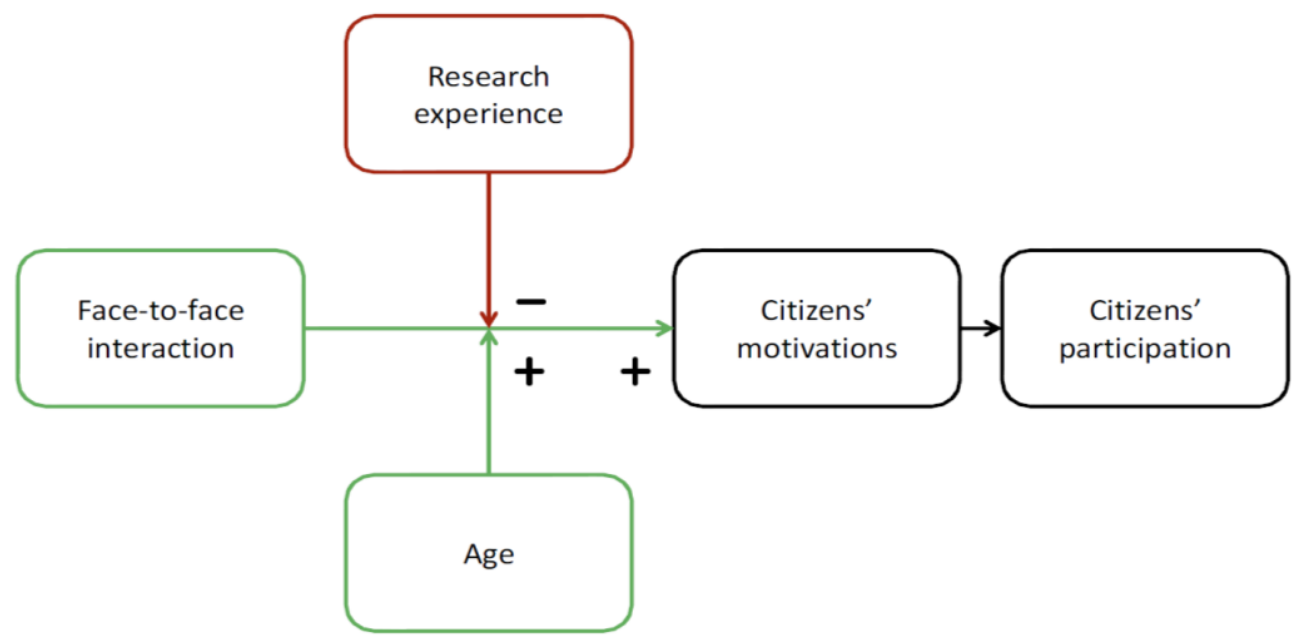

Figure 2 - Graphical representation of the theoretical model. Face-to-face interaction with the researchers is hypothesized to have a positive effect on citizens' motivations that lead to higher participation in citizen science projects, while previous research experience and age are expected to have a negative and positive moderating effect, respectively.

If the theoretical model reported in Figure 2 is confirmed, it will be possible to interpret the effects of each independent and moderating variable on the dependent variable through a linear regression model. Such a model allows for assessing the impact of each contributing factor through the weights associated with them. Thus, we posit the following linear regression model:

$$
Y=\alpha+\beta_{1} x_{1}+\beta_{2} x_{2}+\beta_{3} x_{3}+\beta_{4} x_{4}
$$

Here, the dependent variable $Y$ is the overall motivation, computed as the sum of the survey scores of each motivational driver; $\alpha$ is the overall motivation before the face to-face interaction; $\beta_{1}$ is the coefficient related to the binary independent variable of the face-to-face impact $x_{1}(=1$ if they had faceto-face interaction and $=0$ if not); $\beta_{2}$ is the coefficient related to the effect of age as a binary moderating variable $x_{2}\left(=1\right.$ if they are older than the median age and $=0$ otherwise); $\beta_{3}$ is the coefficient related to the effect of previous research experience binary moderating variable $x_{3}(=1$ if they had a previous research experience and $=0$ if not); and $\beta_{4}$ is the coefficient related to the effect of the gender binary control variable $x_{4}(=1$ if they are male and $=0$ if they are female) to check for eventual differences between males and females. 
An alternative hypothesis that should be contemplated when explaining Hypothesis 1 is that the direct experience with the technological elements of the project and the familiarization with the project, rather than the face-to-face interaction with the researchers, are responsible for the positive effect on the motivations. This alternative hypothesis would be favored by previous studies conducted in robotmediated physical therapy and human machine interactions, which have demonstrated that individual behavior is positively affected by the interaction with robots (Bainbridge et al., 2011; Goodrich and Schultz, 2007; Robins et al., 2004). To evaluate this possibility, ruling out an alternative explanation of the results of this research, a control condition is performed where participants interacted with the Brooklyn Atlantis platform without a face-to-face experience with the researchers.

\subsection{Data collection protocol}

Citizens' motivational drivers were studied through a split survey, one before and one after the face-toface interaction. The method of investigation is a measure-manipulate-measure experiment. The inhabitants of Brooklyn, around 2.5 million people, are the individuals mainly affected by the pollution

of the Gowanus Canal that passes through the borough. The experiment was carried out along the canal to let the participants interact with the researchers while sampling real data with the aquatic robot. Among the possible locations, we opted for a public park in front of a large supermarket (intersection of 3rd street and 3rd avenue in Brooklyn, NY) such that all citizens living in the area and going for groceries would have the chance to be included in this research. The collection of data occurred over weekends with favorable weather when no other activity was carried out in the area. Potential subjects voluntarily approached a stand comprised of a tent, tables, and computer equipment that the researchers use for data collection in the canal. The stand was advertised with a New York University banner adjacent to the tent (Figure 3 ). 


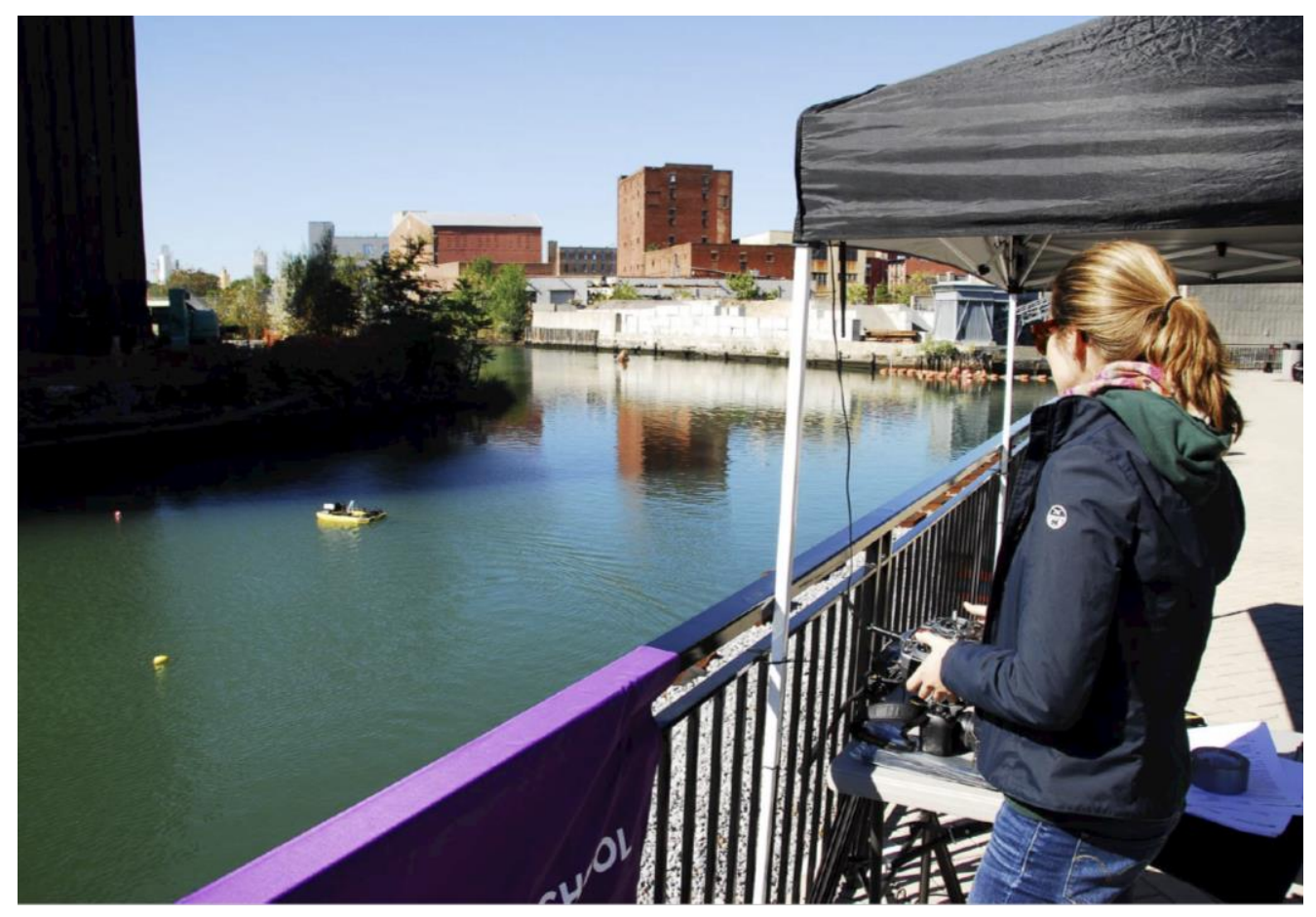

Figure 3 - The Brooklyn Atlantis project stand was located in the public park in front of a supermarket (intersection of 3rd street and 3rd avenue in Brooklyn, NY). It was composed of: an NYU Tandon School of Engineering banner, tent, aquatic robot, radio controller, and laptop.

When a participant arrived at the stand, a researcher briefly described the aims of the Brooklyn Atlantis project, and the capabilities of the aquatic robot that was already in the water. Specifically, the researcher concisely explained what data the aquatic robot is able to collect, that is photos and water quality measures, how these data are used by the Brooklyn Atlantis project, and how citizen scientists could help the project by volunteering their time to perform data analysis. This initial explanation was necessary to offer sufficient background for the potential participant to decide whether to be involved in the activity and knowledgeably complete the surveys. This introduction was very brief and lasted approximately one minute, at the end of which, if the subject agreed to participate in the scientific task in cooperation with the researchers, the first survey was administered. After the introduction, the participant contributed to the project in collaboration with the researchers for approximately 15 minutes, by collecting images and water quality data, in particular dissolved oxygen, with the aquatic robot. In addition, the participant had the possibility to interact with the researchers asking questions and receiving on the spot information about the Brooklyn Atlantis citizen science, such as water quality importance, Gowanus Canal history, online active community, hardware and software details of the project, etc. The data was presented to the participant in real-time on a laptop computer at the stand, 
through a custom-developed LabVIEW interface (Release 13, NI, USA) (Figure 4(a)), and, later, uploaded on the Brooklyn Atlantis web-based platform to be available for the community.

The participants also received the necessary scientific insight from the researchers regarding the data gathered by the aquatic robot to analyze the dissolved oxygen data they collect on the spot, giving an understanding of which values were appropriate for clean water and how far the water analyzed was from acceptable levels. Current progress on the remediation of the canal was also discussed with the participants (Figure 4(b)), as well as water quality data from previous years collected by the Brooklyn Atlantis system. After completing the data collection task, a second survey was administered to the participants with no attrition as everyone who filled in the first survey completed also the second one.
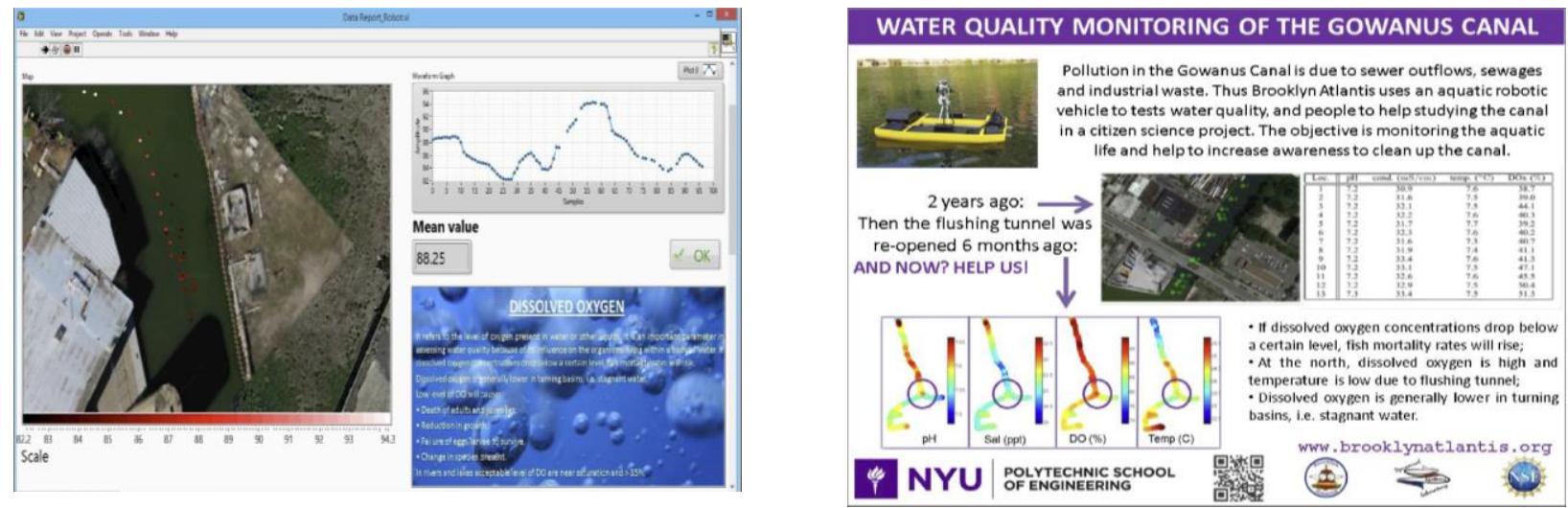

Figure 4 - Supporting material displayed by the researchers on their laptop during the interaction with the participant taking place at a public park in front of a supermarket at the intersection of $3^{\text {rd }}$ street and $3^{\text {rd }}$ avenue in Brooklyn, NY: (a) LabVIEW software for real time analysis of data collected on the spot by participants; and (b) scientific analysis carried out in the canal in previous years to explain the importance of dissolved oxygen level improvements (evidenced by comparison with data collected by participants in this experiment).

With respect to the control condition, a similar protocol was followed to measure the motivations of participants who had not experienced a face-to-face interaction with the researchers. When the participants arrived at the stand, they received the same initial information on the Brooklyn Atlantis project and the capabilities of the robot for them to decide whether to be involved. In case they decided to participate, they were instructed to fill in the first survey. Then, participants collected the data through the aquatic robot without directly interacting with the researchers, asking questions or receiving additional information about the project. At the end of the experience, they completed the second survey with no attrition either in the control condition as everyone who filled in the first survey completed also the second one. 


\subsection{Participants}

The study was carried out on a sample of 86 subjects who voluntarily participated in the experiment: 65 participants were exposed to the face-to-face interaction (face-to-face, FTF, group), and 21 comprised the control group (Table 1). These sample sizes are adequate to run a linear regression model with four variables as greater 5 times the number of predictors (Austin and Steyerberg, 2015). The control group was collected to support our hypothesis against alternative explanations. The control group was smaller in size, due to its focused use in our statistical design. As explained in the data collection protocol, the experiment sample is expected to be representative of the population mostly affected by the outcomes of the citizen science project, offering some basis for the generalizability of the results. The inclusion criteria were an age of 18 years or more, and willingness to voluntarily participate. Through the first survey instrument, the following data about the participant were collected (Table 1$)$ : gender $(0=$ female and $1=$ male, while no participant chose the gender neutral option); if they earned a $\mathrm{PhD}(1=\mathrm{PhD}$ and $0=$ no $\mathrm{PhD}$ ); age (continuous variable); and if they have previously participated in the Brooklyn Atlantis project. Concerning age, a binary value was used in the linear regression to distinguish if the participant was below or above the FTF group median of the age of 35 years old ( 1 if above the median and 0 otherwise). The descriptive demographics regarding the FTF reported a population of $66 \%$ male, with an average age of $36 \pm 10$ years. Concerning the education level, there was a limited coverage of $\mathrm{PhDs}$, whereby only 9 out of 65 participants had completed a doctorate. The higher concentration of individuals holding a $\mathrm{PhD}$ in comparison with the whole US population (13\% vs $3 \%$ respectively) (United States Census Bureau, 2014) is likely due to the gentrification of the Gowanus canal neighborhood. Moreover, we consistently observed a large fraction of $\mathrm{PhDs}$ also in the control group, which is $19 \%$. None of the participants previously participated in Brooklyn Atlantis, and was therefore not influenced by previous experience with the project.

Table 1 - Age is a continuous variable, Gender is a binary variable that is equal to 1 for male and it is 0 for female, and Research experience is a binary variable that is equal to 1 if the participant earned a $\mathrm{PhD}$ and it is 0 otherwise.

Observations Mean Std. Dev.

\begin{tabular}{lcccccc}
\hline & FTF & Control & FTF & Control & FTF & Control \\
\hline Age & 65 & 21 & 35.81 & 35.00 & 10.89 & 7.76 \\
\hline Gender & 65 & 21 & 0.66 & 0.80 & 0.47 & 0.40 \\
\hline Research experience & 65 & 21 & 0.13 & 0.19 & 10.89 & 0.40 \\
\hline
\end{tabular}




\subsection{Survey indices}

The motivational drivers analyzed in this study, based on technology-mediated social participation literature (Nov et al., 2014; Oreg and Nov, 2008) were:

- $\mathrm{COL}=$ Collective motives: importance attributed to the project environmental goal;

- $\quad$ IDNTP = Identification: in the group scientific aim;

- $\quad$ NORM = Norm oriented motives: expectation regarding reactions of family and friends;

- $\quad \mathrm{REP}=$ Reputation: interest in improving personal reputation;

- $\quad \mathrm{SOC}=$ Social interaction: likelihood in participating in social community;

- $\quad$ INTGEN = Intrinsic motives: enjoyment in participating;

- $\quad \mathrm{INF}=$ Information seeking: interest towards gaining knowledge on the topic.

The abovementioned motivational drivers were studied in a set of two surveys, through questions that are not explicitly connected to the motivations types so that participants were not influenced. Each

survey, that is, before the face-to-face interaction (Table 2) and after (Table 3), were graded following a 1-7 Likert scale, with 1 being strongly disagree and 7 being strongly agree with the statement reported. In both surveys, a question pertaining to each motivational driver was asked to compare participant response before and after the face to-face interaction. 
Table 2 - Survey before the face-to-face interaction (the column "motivational driver" was not shown to participants).

\begin{tabular}{|c|c|c|}
\hline Question & Answer & \\
\hline \multicolumn{3}{|l|}{ Age } \\
\hline Gender & Male; Female; Gender neutral & \\
\hline Education & Ph.D.; No Ph.D. & \\
\hline Motivational driver & Statement to be graded & Mark \\
\hline INTGEN1 & Participating in collecting and analyzing water quality data is fun. & $1-7$ \\
\hline INF1 & Learning more about water quality is important to me. & $1-7$ \\
\hline COL1 & $\begin{array}{l}\text { Contributing to the collection of scientifically useful data is } \\
\text { important to me. }\end{array}$ & $1-7$ \\
\hline NORM1 & $\begin{array}{l}\text { My family will think positively about my participation in this } \\
\text { environmental concerned project }\end{array}$ & $1-7$ \\
\hline IDNTP1 & I identify with the communities active in environmental issues. & $1-7$ \\
\hline$R E P 1$ & $\begin{array}{l}\text { My reputation as a valuable contributor to an environmental } \\
\text { concerned project is important to me. }\end{array}$ & $1-7$ \\
\hline SOC1 & $\begin{array}{l}\text { Developing a personal exchange with other scientists and } \\
\text { participants is important to me. }\end{array}$ & $1-7$ \\
\hline
\end{tabular}

Table 3 - Survey after the face-to-face interaction (the column "motivational driver" was not shown to participants).

\begin{tabular}{|c|c|c|}
\hline Question & Answer & \\
\hline \multicolumn{3}{|l|}{ Age } \\
\hline Gender & Male; Female; Gender neutral & \\
\hline Education & Ph.D.; No Ph.D. & \\
\hline Motivational driver & Statement to be graded & Mark \\
\hline COL2 & Advancing scientific research is important to me. & $1-7$ \\
\hline REP2 & $\begin{array}{l}\text { Having other researchers and participants appreciate my } \\
\text { contribution is important to me. }\end{array}$ & $1-7$ \\
\hline$S O C 2$ & $\begin{array}{l}\text { Meeting people and making friends through scientific projects } \\
\text { is important to me. }\end{array}$ & $1-7$ \\
\hline IDNTP2 & $\begin{array}{l}\text { I am proud of my involvement in this environmental concerned } \\
\text { project. }\end{array}$ & $1-7$ \\
\hline NORM2 & $\begin{array}{l}\text { My friends will think positively about my participation in this } \\
\text { environmental concerned project. }\end{array}$ & $1-7$ \\
\hline INTGEN2 & I enjoy participating in data collection. & $1-7$ \\
\hline INF2 & $\begin{array}{l}\text { Keeping up with new information about water quality is important } \\
\text { to me. }\end{array}$ & $1-7$ \\
\hline
\end{tabular}




\subsection{Statistical analysis}

The statistical analyses reported in this section were conducted with STATA (release 12). To study the impact that face-to-face interaction has on participants, and to assess its validity as a technique for motivating new users, the impact on each motivational driver was tested one by one. In addition, the scores of the surveys "pre" and "post" the face-to-face interactions were summed for a comparative statistical analysis on the overall motivation to contribute to citizen science. Being a measuremanipulate-measure experiment, a paired test was used to compare individual and overall motivations, to account for repeated measurements on the same subjects. To choose the appropriate statistical tool for the paired test ( $t$-test or Wilcoxon-Mann-Whitney test), a test of normality was conducted with a skewness-kurtosis test which requires a minimum of 8 observations to combine skewness and kurtosis of a sample to assess the Gaussian distribution (D'Agostino et al., 1990).

To study the effects of age and research experience, these variables were included in a linear regression, starting from the result of $\mathrm{H} 1 \mathrm{~b}$, as moderating variables of the effect bought about by the face-to-face interaction, with gender as the control variable. We tested the linear regression model (Equation (1)), where the dependent variable was the overall motivation, the independent variables were the condition (a binary value for "pre" $=0$ and "post" $=1$ face-to-face interaction), age and previous research were the moderating variables, and gender a control variable. The statistical analyses were conducted at the $p=0.05$ significance level.

To verify that the populations of the control and the FTF groups were not different, the two descriptive statistics were compared with a $t$-test, and, after that, the results from the control group were analyzed using the same procedure described above to highlight the role of face-to-face interactions.

\section{Results}

\subsection{Motivations: increase after the face-to-face interaction}

From the normality test, the distribution of each and every motivation was not found to be Gaussian. Thus, the Wilcoxon- Mann-Whitney paired test (Casella and Berger, 2001) was used to compare the motivational driver "pre" and "post" face-to-face interaction, see Table 4.

The difference between "pre" and "post" face-to-face interactions was statistically significant for each motivational driver, with a $p<0.001$. Specifically, the survey marks of each motivational driver were found to increase from the first to the second survey filled in by those who participated in the 
experiment (Table 4). The most affected motivations are intrinsic (INTGEN) and reputation (REP), with $\mathrm{a}+1.53$ and +1.59 difference, respectively.

Table 4 - Results of the Wilcoxon-Mann-Whitney test to investigate the difference for each motivation of the FTF group after the interaction with the researchers.

\begin{tabular}{lccccc}
\hline "pre" vs "post" motivation & $\boldsymbol{Z}$ & $\boldsymbol{p}$-value & Difference & "pre" value & "post" value \\
\hline INTGEN & -5.54 & 0.000 & 1.53 & 4.89 & 6.43 \\
\hline$I N F$ & -4.53 & 0.000 & 1.10 & 5.36 & 6.48 \\
\hline COL & -5.70 & 0.000 & 1.40 & 5.07 & 6.47 \\
\hline NORM & -4.51 & 0.000 & 1.41 & 4.89 & 6.30 \\
\hline$I D N T P$ & -5.05 & 0.000 & 1.44 & 4.89 & 6.24 \\
\hline REP & -5.57 & 0.000 & 1.59 & 4.66 & 6.15 \\
\hline SOC & -5.60 & 0.000 & 1.35 & 4.72 & 6.07 \\
\hline
\end{tabular}

The normality test for the distributions of the overall motivation "pre" and "post" face to-face interaction was positive; thus, a paired t-test was used for the comparison. The comparison indicates that the two data sets were statistically different $(p<0.001)$, with an increase of +9.75 in the "post" values (Table 5).

Table 5 - Results of the paired $t$-test to investigate the overall motivation increase "post" the experience with the researchers for the FTF and control groups.

\begin{tabular}{lcccc}
\hline & $t$ & $p$-value & Mean & Std. Dev \\
\hline "pre" vs "post" FTF group & -8.16 & 0.000 & 9.75 & 1.19 \\
\hline "pre" vs "post" control group & -0.73 & 0.469 & 0.57 & 3.54 \\
\hline
\end{tabular}

\subsection{Age and previous research experience: moderating effects on the impact of face-to-face interaction}

Age and previous research experience were treated as moderating effects in the model proposed in this paper (Figure 2). Table 6 displays the coefficients $\beta_{1}, \beta_{2}, \beta_{3}$, and $\beta_{4}$ of the linear regression model reported in Equation (1). 
Table 6 - Results of the linear regression for the FTF group. The overall motivation is the dependent variable, the condition ("pre" $=0$ or "post" $=1$ face-to-face interaction) is the independent variable, age and research experience are the moderating variables, and gender is the control variable.

\begin{tabular}{lccc}
\hline $\boldsymbol{p}$-value Fischer & 0.000 & & \\
\hline $\boldsymbol{R}^{\mathbf{2}}$ & 0.367 & & \\
\hline & Coefficient & $\boldsymbol{t}$ & $\boldsymbol{p}$-value \\
\hline Condition & 9.75 & 7.70 & 0.000 \\
\hline Age & 3.71 & 2.86 & 0.005 \\
\hline Research experience & -2.83 & -1.49 & 0.139 \\
\hline Gender & 1.38 & 1.01 & 0.313 \\
\hline Overall motivation & 32.23 & 23.43 & 0.000 \\
\hline
\end{tabular}

The increase in the overall motivation from the face-to-face interaction is confirmed in this analysis, with a $p<0.001$. The age variable had a significant effect on overall motivation $(p=0.005)$ with a positive impact of +3.71 . On the other hand, previous research experience and gender did not have a significant role on the overall motivation ( $p=0.139$ and $p=0.313$ respectively). The linear regression posed in Equation (1), that reconstructs and quantify the effects brought about by the independent and control variables on the overall motivations takes the form:

$$
Y=32.23+9.75 x_{1}+3.71 x_{2}-2.83 x_{3}+1.38 x_{4} \quad \text { Equation (2) }
$$

\subsection{Motivations: no increase in the absence of face-to-face interactions}

In the control group, the average age, research experience, and gender distributions are highly comparable to the FTF group, as reported in Table 1. Specifically, comparison between the groups showed no significant difference with respect to age, research experience, and gender $(p>0.16$, Table 7).

Table 7 - Results of the $t$-test on independent and control variables: comparison between FTF and control groups.

\begin{tabular}{lcccc}
\hline & $\boldsymbol{t}$ & $\boldsymbol{p}$-value & Mean & Std. Dev. \\
\hline Age & 0.35 & 0.729 & 1.19 & 15.52 \\
\hline Research experience & 0.43 & 0.665 & 0.04 & 0.49 \\
\hline Gender & 1.45 & 0.162 & 0.19 & 0.60 \\
\hline
\end{tabular}


Different than the FTF group, a robust increase in motivations was not observed for participants in the control condition. Analyzing the individual motivational drivers, only those associated with norm oriented motives were found to increase after the experience $(p<0.05)$, whereby all the other motivations were not affected by the experience $(p>0.08$, Table 8). Going further into the overall levels of motivations, they were indistinguishable before and after the experience $(p>0.46$, Table 5).

Table 8 - Results of the Wilcoxon-Mann-Whitney test to investigate the difference for each motivation of the control group after the interaction with the researchers.

\begin{tabular}{lccc}
\hline "pre" vs "post" motivation & $\boldsymbol{Z}$ & $\boldsymbol{p}$-value & Difference \\
\hline INTGEN & -1.73 & 0.083 & 0.29 \\
\hline$I N F$ & -0.95 & 0.340 & 0.19 \\
\hline COL & -0.87 & 0.380 & 0.09 \\
\hline NORM & -2.59 & 0.009 & -0.52 \\
\hline IDNTP & -1.42 & 0.154 & -0.33 \\
\hline REP & -1.35 & 0.176 & 0.52 \\
\hline SOC & -1.11 & 0.285 & 0.24
\end{tabular}

In addition, differently than the FTF condition, in the control condition none of the moderating variables of the linear regression model in Equation 1 had a significant role in the overall level of motivation (Table 9).

Table 9 - Results of the linear regression for the control group. The overall motivation is the dependent variable, the condition ("pre"=zero or "post"=one face-to-face interaction) is the independent variable, age and research experience are the moderating variables, and gender is the control variable.

\begin{tabular}{lccc}
\hline $\boldsymbol{p}$-value Fischer & 0.171 & & \\
\hline $\boldsymbol{R}^{\mathbf{2}}$ & 0.155 & & \\
\hline & Coefficient & $\boldsymbol{t}$ & $\boldsymbol{p}$-value \\
\hline Condition & 0.571 & 0.29 & 0.771 \\
\hline Age & 4.32 & 2.00 & 0.053 \\
\hline Research experience & -0.80 & -0.30 & 0.767 \\
\hline Gender & -6.61 & -2.27 & 0.029 \\
\hline Overall motivation & 43.36 & 15.59 & 0.000
\end{tabular}

18 of 30 


\section{Discussion}

The problem of maintaining citizen scientists motivated to contribute in data collection and analysis is common to most citizen science projects (Laut et al., 2016; Nov et al., 2014). A key finding of this work is the empirical evidence of the impact brought about by interaction with the researchers on several motivational aspects at the basis of their contribution. The survey filled in before the face toface interaction indicated an average grade below 5 out of 7 on the Likert scale for each of the motivations, with two exceptions, 5.36 and 5.07, for information seeking and collective motives, respectively (Table 4). This suggests that the participants, before starting to contribute to the citizen science project, were particularly interested in gaining knowledge through participation in the tasks, and they were concerned with the collective environmental goals of the effort. At the end of the experience with the researchers, the marks given in the second survey for each motivational driver increased by more than 1 point to values above 6 out of 7 on the Likert scale (Table 4). Intrinsic motivations were the most positively influenced (from 4.89 to 6.43 ), due to the enjoyment in participating in data collection tasks together with professional scientists, and reputation (from 4.66 to 6.15), likely attributed to the participants' knowledge that their findings would have been shared through the whole Brooklyn Atlantis web based platform. Importantly, intrinsic and reputation motivations are among the most important factors for volunteers' quantity of contributions in citizen science projects (Nov et al., 2014).

Thus, face-to-face interaction could potentially serve as a means of increasing the quantity of online contributions. Such an interaction also positively impacted all the other motivational drivers considered in our study: identification, by enabling the participants that interacted with the researchers to become increasingly aware and keen to the environmental aim of the project; norm oriented and collective motivations, by increasing participants' awareness of the social purposes of the project and help them apprehending how much their involvement could be respected by families and friends; social interaction, whereby participants could feel to be more part of an active community after the experience; and information seeking, associated with the possibility offered to the participants to gain knowledge through their efforts. Moreover, the outcomes of this work evidence an increase in overall motivation to contribute, scored as the sum of motivations scores from the surveys, after the face-toface interactions.

The positive impact on motivations brought about by the interaction with the researchers, an unconventional experience in the field of citizen science, is due to the exposure to citizen science 19 of 30 
project aspects that are often masked by the web-based interface. As a consequence, a limitation of face-to-face interactions is that they can only be directly implemented for participants living in the vicinity of the project site, while the entire online community may not benefit from them. However, this may not be common across top-down technology-mediated citizen science projects, whose success is based on the ability to reach a broad audience (Franzoni and Sauermann, 2014), beyond specific community living a target neighborhood. For Brooklyn Atlantis (Laut et al., 2014) and possibly other environmental citizen science projects, citizens living nearby the environmental problem represent the majority of the online community. Future work should seek to overcome this limitation by understanding if virtual interactions (for example, by videoconferencing) with the researchers could attain a similar benefit for online participants, extending the basin for technology-mediated citizen science beyond local community members. Given the facilitating role of face-to-face interactions on mutual acceptance and knowledge transfer we speculate that such positive effects would be diminished (Goffman, 2005; Song et al., 2007).

Our linear regression (Equation (2)) analysis suggests that age plays an important role as a moderating variable, whereby older individuals reacted more positively to the face-to-face interaction. This finding is in agreement with previous studies that have demonstrated that older individuals tend to have an increased attention for environmental issues, which are central for the Brooklyn Atlantis and citizen science projects in general (Aminrad et al., 2011; Wiernik et al., 2013). Thus, we posit that targeted implementations of face-to-face interaction could focus on older participants, whose motivations would likely be more impacted.

In contrast with hypothesis $2 \mathrm{~b}$, the results of the experiment not demonstrate a significant moderating effect of previous research experience, whereby individuals who earned a $\mathrm{PhD}$ degree were expected to be less positively impacted by the face-to-face interaction (Knutson et al., 2010). Likely, this should be attributed to the relatively small sample size, with only nine individuals holding a $\mathrm{PhD}$ degree. For this reason, we did not distinguished among the various types of $\mathrm{PhD}$ earned, but we distinguished only among previous research experience or collaborations with scientists and scholars, or not. Therefore another possible explanation for the non-significance of the result in our research could be that only some subjects offers practical technological research experience similar to those of the Brooklyn Atlantis project and broadly to those of citizen science. Alternatively, we could hypothesize that the robotics elements of the project reduced the effect of participants' previous research experience by offering, across the sample, a salient novel stimulus in the form of robotics-based environmental 20 of 30 
science. Future studies on larger samples and different $\mathrm{PhD}$ subjects and different platforms will clarify the role of previous research experience on the effectiveness of the proposed face-to-face interaction.

Through a control experiment, consisting of participant interaction with the aquatic robot but not with the professional researchers, we also isolated the positive effects on participant motivations brought about the interaction with the aquatic robot from those due to the face-to-face experience. Our results indicate that motivations do not increase due to the sole interactions with the robotic hardware. A possible explanation is that the face-to-face experience with the researchers is necessary to increase participant motivations, while interaction with the aquatic robot plays a secondary role. The interaction with the robot could be considered a form of gamification, which has been recently proposed as a valid approach to leverage gaming motivations behind the entertainment context (Robson et al., 2015). However, our control study suggests that gamification alone may not be sufficient to motivate participants. This result offers indirect evidence for the potential use of face-to-face interactions, based on Piskorski social strategies (Piskorski, 2011), beyond robotics-based citizen science.

A limitation of this study is that we cannot isolate the individual effect of the information offered to the participants by the researchers, from the interaction itself. From a practical point of view, it is rather challenging to dissociate these elements, whereby participants in our study were not familiar with the Brooklyn Atlantis projects, and, without a prior explanation of the project, it would have been difficult for them to perceive our team as authentic researchers. Future studies should consider different, more consolidated, citizen science projects, in which participants knowledge regarding the project activities and its scientific value could be easier to grasp, leaving only the interaction with the researchers as the independent variable.

\section{Conclusions and further developments}

In summary, the contribution of this research is threefold: it demonstrates the possibility of increasing participants' motivations through face-to-face interactions with researchers in the context of technology mediated citizen science; it quantifies the extent of the positive effect of face-to-face interactions on participants' motivations; and assesses the moderating effect of age on the role that face-to-face interactions play on participants' motivations, thus identifying a target audience in the context of environmental monitoring. Our results are expected to contribute to the literature on volunteers' motivations in citizen science projects (Nov et al., 2014; Oreg and Nov, 2008; Raddick et al., 2010), by showing the positive effects of social connections with the researchers to motivate participants in the 
context of social strategies (Piskorski, 2014). The technique proposed herein may aid in the design of effective interventions to increase participants' motivations to contribute to citizen science projects, which is a crucial issue in citizen science (Franzoni and Sauermann, 2014). The interactions with researchers may aid in the implementation of ambitious and data-intensive research projects and positively impacting scientific literacy and environmental awareness (Bonney et al., 2009; Gouveia et al., 2004; Haklay, 2013; Nov et al., 2014; Paul et al., 2014; Trumbull et al., 2000). Toward this aim, it may be important to evaluate the effect of face-to-face interaction on longer time segments in the Brooklyn Atlantis project, to quantify participants' performance and elucidate the frequency and extent of effective interventions.

Citizen science projects are often in need of large data collection and analysis, and many of them fail due to limited participation (Dahlander and Piezunka, 2014; Garcia Martinez and Walton, 2014; Iriberri and Leroy, 2009; Langner and Seidel, 2014; Ling et al., 2005). The results of this study may help researchers and practitioners of citizen science devise means to stimulate participants' motivations. Private companies have also started to embrace contributions from outside the boundaries of their firm (Benner and Tushman, 2015; Michelino et al., 2015; West and Lakhani, 2008) to take advantage of a wide variety of expertise and resources from the crowd (Boudreau and Lakhani, 2013, 2009; Jeppesen and Lakhani, 2010), by blending offline and online community behaviors (Langner and Seidel, 2014). The theoretical underpinnings and empirical evidence of our study could aid in developing effective means for public and private managers dealing with crowd science projects to increase participants' motivation to contribute from outside organization boundaries, especially in the context of environmental problems.

\section{Ethics statement}

This study was approved by the Institutional Review Board of the New York University Tandon School of Engineering, and conducted by researchers certified by the university to conduct experiments with people.

\section{Funding}

This work was supported by the "National Science Foundation" under Grant \# BCS-1124795 and under Grant \# CBET-1547864, and by the "Ministero dell'Istruzione, dell'Universita' e della Ricerca" under 
Grant \# PRIN 2010H37KAW. The funders had no role in study design, data collection and analysis, decision to publish, or preparation of the manuscript.

\section{Acknowledgements}

The authors would like to gratefully acknowledge Prof. Raffaele Oriani for useful suggestions on the research design, Dr. Eduardo Palermo for his contribution to the development of the software for the experiments, and Mauro De Bellis for his help in organizing the set up for the face-to-face interactions. We are thankful to the anonymous reviewers for their detailed and constructive feedback that has helped improve the work and its presentation. 


\section{References}

Aminrad, Z., Zakaria, S.Z.B.S., Hadi, A.S., 2011. Influence of age and level of education on environmental awareness and attitude: case study on Iranian Students in Malaysian Universities. The Social Sciences 6, 15-19.

Andrews, D.C., 2002. Audience-specific online community design. Communications of the ACM 45, 64-68.

Austin, P.C., Steyerberg, E.W., 2015. The number of subjects per variable required in linear regression analyses. Journal of Clinical Epidemiology 68, 627-636. doi:10.1016/j.jclinepi.2014.12.014

Bainbridge, W.A., Hart, J.W., Kim, E.S., Scassellati, B., 2011. The benefits of interactions with physically present robots over video-displayed agents. International Journal of Social Robotics 3, $41-52$.

Baker, S.M., Marshak, H.H., Rice, G.T., Zimmerman, G.J., 2001. Patient participation in physical therapy goal setting. Physical Therapy 81, 1118-1126.

Becker, M., Caminiti, S., Fiorella, D., Francis, L., Gravino, P., Haklay, M.M., Hotho, A., Loreto, V., Mueller, J., Ricchiuti, F., others, 2013. Awareness and learning in participatory noise sensing. PLoS ONE 8, e81638.

Benner, M.J., Tushman, M., 2015. Reflections on the 2013 Decade Award:" Exploitation, Exploration, and Process Management: The Productivity Dilemma Revisited" ten years later. Academy of Management Review amr-2015.

Bergendahl, M., Magnusson, M., Björk, J., 2015. Ideation High Performers: A Study of Motivational Factors. Creativity Research Journal 27, 361-368. doi:10.1080/10400419.2015.1088266

Blumer, H., 1986. Symbolic interactionism: Perspective and method. Univ of California Press.

Bonney, R., Cooper, C.B., Dickinson, J., Kelling, S., Phillips, T., Rosenberg, K. V., Shirk, J., 2009. Citizen Science: A Developing Tool for Expanding Science Knowledge and Scientific Literacy. BioScience 59, 977-984. doi:10.1525/bio.2009.59.11.9

Bonney, R., LaBranche, M., 2004. Citizen science: Involving the public in research. ASTC Dimensions 13.

Boudreau, K.J., Lakhani, K.R., 2013. Using the crowd as an innovation partner. Harvard business review $91,60-69$.

Boudreau, K.J., Lakhani, K.R., 2009. How to Manage Outside Innovation. MITSloan Management Review 50, 68-77. doi:Article

Brabham, D.C., 2010. Moving the crowd at Threadless: Motivations for participation in a crowdsourcing application. Information, Communication \& Society 13, 1122-1145.

24 of 30 
Capdevila, I., Zarlenga, M.I., 2015. Smart City or Smart Citizens? The Barcelona Case. Journal of strategy and management 1-16. doi:10.2139/ssrn.2585682

Casella, G., Berger, R., 2001. Statistical Inference, Second edi. ed. Duxbury.

Chesbrough, H.W., 2006. Open Business Models: How to Thrive in the New Innovation Landscape, Harvard Business Press. doi:10.1111/j.1540-5885.2008.00309_1.x

Conrad, C.C., Hilchey, K.G., 2011. A review of citizen science and community-based environmental monitoring: Issues and opportunities. Environmental Monitoring and Assessment 176, 273-291. doi:10.1007/s10661-010-1582-5

D’Agostino, R.B., Belanger, A., D’Agostino Sr., R.B., D’Agostino Jr., R.B., 1990. A Suggestion for Using Powerful and Informative Tests of Normality. American Statistician. doi:10.2307/2684359

Dahlander, L., Piezunka, H., 2014. Open to suggestions: How organizations elicit suggestions through proactive and reactive attention. Research Policy 43, 812-827. doi:10.1016/j.respol.2013.06.006

Danielsen, F., Burgess, N.D., Balmford, A., Donald, P.F., Funder, M., Jones, J.P.G., Alviola, P., Balete, D.S., Blomley, T., Brashares, J., Child, B., Enghoff, M., Fjelds??, J., Holt, S., H??bertz, H., Jensen, A.E., Jensen, P.M., Massao, J., Mendoza, M.M., Ngaga, Y., Poulsen, M.K., Rueda, R., Sam, M., Skielboe, T., Stuart-Hill, G., Topp-J??rgensen, E., Yonten, D., 2009. Local participation in natural resource monitoring: A characterization of approaches. Conservation Biology 23, 31-42. doi:10.1111/j.1523-1739.2008.01063.x

Deci, E.L., Ryan, R.M., 2000. The "what" and "why" of goal pursuits: Human needs and the selfdetermination of behavior. Psychological inquiry 11, 227-268.

Devictor, V., Whittaker, R.J., Beltrame, C., 2010. Beyond scarcity: Citizen science programmes as useful tools for conservation biogeography. Diversity and Distributions 16, 354-362. doi:10.1111/j.14724642.2009.00615.x

Dickinson, J.L., Shirk, J., Bonter, D., Bonney, R., Crain, R.L., Martin, J., Phillips, T., Purcell, K., 2012. The current state of citizen science as a tool for ecological research and public engagement. Frontiers in Ecology and the Environment 10, 291-297. doi:10.1890/110236

Dickinson, J.L., Zuckerberg, B., Bonter, D.N., 2010. Citizen science as an ecological research tool: challenges and benefits. Annual Review of Ecology, Evolution, and Systematics 41, 149-172.

Fairweather, P.G., 1991. Statistical power and design requirements for environmental monitoring. Marine and Freshwater Research 42, 555-567.

Felin, T., Zenger, T.R., 2011. Information aggregation, matching and radical market-hierarchy hybrids: Implications for the theory of the firm. Strategic Organization, forthcoming.

Feller, J., 2005. Perspectives on free and open source software. MIT Press. 
Fore, L.S., Paulsen, K., O’Laughlin, K., 2001. Assessing the performance of volunteers in monitoring streams. Freshwater Biology 46, 109-123.

Franzoni, C., Sauermann, H., 2014. Crowd science: The organization of scientific research in open collaborative projects. Research Policy 43, 1-20. doi:10.1016/j.respol.2013.07.005

Garcia Martinez, M., Walton, B., 2014. The wisdom of crowds: The potential of online communities as a tool for data analysis. Technovation 34, 203-214. doi:10.1016/j.technovation.2014.01.011

Gilson, L.L., Lim, H.S., D’Innocenzo, L., Moye, N., 2012. One size does not fit all: Managing radical and incremental creativity. Journal of Creative Behavior 46, 168-191. doi:10.1002/jocb. 12

Giustiniano, L., Bolici, F., 2012. Organizational trust in a networked world: Analysis of the interplay between social factors and Information and Communication Technology. Journal of Information, Communication and Ethics in Society 10, 187-202.

Goffman, E., 2005. Interaction ritual: Essays in face to face behavior. AldineTransaction.

Goodrich, M.A., Schultz, A.C., 2007. Human-robot interaction: a survey. Foundations and Trends in Human-computer Interaction 1, 203-275.

Gouveia, C., Fonseca, A., Camara, A., Ferreira, F., 2004. Promoting the use of environmental data collected by concerned citizens through information and communication technologies. Journal of Environmental Management 71, 135-154.

Haklay, M., 2013. Citizen science and volunteered geographic information: Overview and typology of participation, in: Crowdsourcing Geographic Knowledge. Springer, pp. 105-122.

Hasenfratz, D., Saukh, O., Sturzenegger, S., Thiele, L., 2012. Participatory Air Pollution Monitoring Using Smartphones, in: Mobile Sensing: From Smartphones and Wearables to Big Data. Associaton for Computing Machinery, Beijing, China.

Hertel, G., Niedner, S., Herrmann, S., 2003. Motivation of software developers in Open Source projects: an Internet-based survey of contributors to the Linux kernel. Research Policy 32, 1159-1177. doi:10.1016/S0048-7333(03)00047-7

Holohan, A., Garg, A., 2005. Collaboration Online: The Example of Distributed Computing. Journal of Computer-Mediated Communication 10, 00-00. doi:10.1111/j.1083-6101.2005.tb00279.x

Iriberri, A., Leroy, G., 2009. A life-cycle perspective on online community success. ACM Computing Surveys 41, 1-29. doi:10.1145/1459352.1459356

Jeppesen, L.B., Lakhani, K.R., 2010. Marginality and problem-solving effectiveness in broadcast search. Organization science 21, 1016-1033.

Jordan, R., Singer, F., Vaughan, J., Berkowitz, A., 2008. What should every citizen know about ecology? Frontiers in Ecology and the Environment 7, 495-500.

26 of 30 
Klandermans, B., 1996. The social psychology of protest. Oxford: Blackwell.

Klandermans, P.G., 2003. Collective political action. Oxford: Oxford University Press.

Knutson, K., Smith, J., Wallert, M.A., Provost, J.J., 2010. Bringing the excitement and motivation of research to students; Using inquiry and research-based learning in a year-long biochemistry laboratory. Biochemistry and Molecular Biology Education 38, 317-323.

Koskinen, K.U., Vanharanta, H., 2002. The role of tacit knowledge in innovation processes of small technology companies. International journal of production economics 80, 57-64.

Lakhani, K., Wolf, R.G., 2003. Why hackers do what they do: Understanding motivation and effort in free/open source software projects. MIT Sloan working paper 4425.

Lakhani, K.R., Von Hippel, E., 2003. How open source software works: "free" user-to-user assistance. Research Policy 32, 923-943. doi:10.1016/S0048-7333(02)00095-1

Langner, B., Seidel, V.P., 2014. Sustaining the Flow of External Ideas: The Role of Dual Social Identity across Communities and Organizations. Journal of Product Innovation Management 32, 522-538. doi:10.1111/jpim. 12216

Laut, J., Cappa, F., Nov, O., Porfiri, M., 2016. Increasing Citizen Science Contribution Using a Virtual Peer. Journal of the Association for Information Science and Technology Accepted $\mathrm{p}$.

Laut, J., Cappa, F., Nov, O., Porfiri, M., 2015. Increasing Patient Engagement in Rehabilitation Exercises Using Computer-Based Citizen Science. PLoS ONE 10, e0117013.

Laut, J., Henry, E., Nov, O., Porfiri, M., 2014. Development of a mechatronics-based citizen science platform for aquatic environmental monitoring. IEEE/ASME Transactions on Mechatronics 19, 1541-1551. doi:10.1109/TMECH.2013.2287705

Ling, K., Beenen, G., Ludford, P., Wang, X., Chang, K., Li, X., Cosley, D., Frankowski, D., Terveen, L., Rashid, A.M., others, 2005. Using social psychology to motivate contributions to online communities. Journal of Computer-Mediated Communication 10, 0.

Lovett, G.M., Burns, D.A., Driscoll, C.T., Jenkins, J.C., Mitchell, M.J., Rustad, L., Shanley, J.B., Likens, G.E., Haeuber, R., 2007. Who needs environmental monitoring? Frontiers in Ecology and the Environment 5, 253-260.

MacIntyre, A., 1984. After virtue. University of Notre Dame Press Notre Dame.

Michelino, F., Cammarano, A., Lamberti, E., Caputo, M., 2015. Knowledge Domains, Technological Strategies and Open Innovation. Journal of technology management \& innovation 10, 50-78.

Newman, G., Wiggins, A., Crall, A., Graham, E., Newman, S., Crowston, K., 2012. The future of Citizen science: Emerging technologies and shifting paradigms. Frontiers in Ecology and the Environment 10, 298-304. doi:10.1890/110294 
Nov, O., Arazy, O., Anderson, D., 2014. Scientists@ Home: what drives the quantity and quality of online citizen science participation? PLoS ONE 9, e90375.

O’Mahony, S., Ferraro, F., 2007. The emergence of governance in an open source community. Academy of Management Journal 50, 1079-1106.

Oreg, S., Nov, O., 2008. Exploring motivations for contributing to open source initiatives: The roles of contribution context and personal values. Computers in Human Behavior 24, 2055-2073.

Paul, K., Quinn, M.S., Huijser, M.P., Graham, J., Broberg, L., 2014. An evaluation of a citizen science data collection program for recording wildlife observations along a highway. Journal of Environmental Management 139, 180-187. doi:10.1016/j.jenvman.2014.02.018

Piskorski, M.J., 2014. A Social Strategy: How We Profit from Social Media. Princeton University Press.

Piskorski, M.J., 2011. Social strategies that work. Harvard Business Review 89, 116-122.

Preece, J., Shneiderman, B., 2009. The reader-to-leader framework: Motivating technology-mediated social participation. AIS Transactions on Human-Computer Interaction 1, 13-32.

Raddick, M.J., Bracey, G., Carney, K., Gyuk, G., Borne, K., Wallin, J., Jacoby, S., Planetarium, A., 2009. Citizen science: status and research directions for the coming decade. AGB Stars and Related Phenomenastro 2010: The Astronomy and Astrophysics Decadal Survey 46P.

Raddick, M.J., Bracey, G., Gay, P.L., Lintott, C.J., Murray, P., Schawinski, K., Szalay, A.S., Vandenberg, J., 2010. Galaxy Zoo: Exploring the Motivations of Citizen Science Volunteers. Astronomy Education Review 9, 010103. doi:10.3847/AER2009036

Riesch, H., Potter, C., Davies, L., 2013. Combining citizen science and public engagement: the Open AirLaboratories Programme. Journal of Science Communication 12.

Roberts, J.A., Hann, I., Slaughter, S.A., 2006. Understanding the motivations, participation, and performance of open source software developers: A longitudinal study of the Apache projects. Management science 52, 984-999.

Robins, B., Dickerson, P., Stribling, P., Dautenhahn, K., 2004. Robot-mediated joint attention in children with autism: A case study in robot-human interaction. Interaction Studies 5, 161-198.

Robson, K., Plangger, K., Kietzmann, J.H., Mccarthy, I., Pitt, L., 2015. Is it all a game? Understanding the principles of gamification. doi:10.1016/j.bushor.2015.03.006

Ryan, R.L., Kaplan, R., Grese, R.E., 2001. Predicting volunteer commitment in environmental stewardship programmes. Journal of Environmental Planning and Management 44, 629-648.

Sauermann, H., Franzoni, C., 2015. Crowd science user contribution patterns and their implications. Proceedings of the National Academy of Sciences 112, 679-684.

Schroer, J., Hertel, G., 2009. Voluntary Engagement in an Open Web-Based Encyclopedia: Wikipedians 28 of 30 
and Why They Do It. Media Psychology 12, 96-120. doi:10.1080/15213260802669466

Seidel, V.P., Langner, B., 2015. Using an online community for vehicle design: project variety and motivations to participate. Industrial and Corporate Change dtv016.

Seltzer, E., Mahmoudi, D., 2013. Citizen Participation, Open Innovation, and Crowdsourcing: Challenges and Opportunities for Planning. Journal of Planning Literature 28, 3-18. doi: $10.1177 / 0885412212469112$

Silvertown, J., 2009. A new dawn for citizen science. Trends in Ecology \& Evolution 24, 467-471.

Song, M., Berends, H., der Bij, H., Weggeman, M., 2007. The effect of IT and co-location on knowledge dissemination. Journal of Product Innovation Management 24, 52-68.

Stevens, M., Vitos, M., Altenbuchner, J., Conquest, G., Lewis, J., Haklay, M., 2014. Taking Participatory Citizen Science to Extremes. Pervasive Computing, IEEE 13, 20-29.

Sullivan, B.L., Aycrigg, J.L., Barry, J.H., Bonney, R.E., Bruns, N., Cooper, C.B., Damoulas, T., Dhondt, A.A., Dietterich, T., Farnsworth, A., Fink, D., Fitzpatrick, J.W., Fredericks, T., Gerbracht, J., Gomes, C., Hochachka, W.M., Iliff, M.J., Lagoze, C., La Sorte, F.A., Merrifield, M., Morris, W., Phillips, T.B., Reynolds, M., Rodewald, A.D., Rosenberg, K. V., Trautmann, N.M., Wiggins, A., Winkler, D.W., Wong, W.-K., Wood, C.L., Yu, J., Kelling, S., 2014. The eBird enterprise: An integrated approach to development and application of citizen science. Biological Conservation 169, 31-40. doi:10.1016/j.biocon.2013.11.003

Toch, H., 2013. The Social Psychology of Social Movements. (Psychology Revivals) Routledge.

Trumbull, D.J., Bonney, R., Bascom, D., Cabral, A., 2000. Thinking scientifically during participation in a citizen-science project. Science Education 84, 265-275.

Tushman, M., Lakhani, K., Lifshitz-Assaf, H., 2012. Open innovation and organization design. Journal of Organization Design 1, 24-26.

Von Krogh, G., Haefliger, S., Spaeth, S., Wallin, M.W., 2012. Carrots and rainbows: Motivation and social practice in open source software development. MIS quarterly 36, 649-676.

West, J., Lakhani, K.R., 2008. Getting clear about communities in open innovation. Industry and Innovation 15, 223-231.

Wiernik, B.M., Ones, S.D., Dilchert, S., 2013. Age and environmental sustainability: a meta-analysis. Journal of Managerial Psychology 28, 826-856.

Wiggins, A., Crowston, K., 2011. From conservation to crowdsourcing: A typology of citizen science, in: Proceedings of the Annual Hawaii International Conference on System Sciences. doi:10.1109/HICSS.2011.207

Wiggins, A., Crowston, K., 2010. Developing a conceptual model of virtual organisations for citizen 
science. International Journal of Organisational Design and Engineering 1, 148-162. doi:101504IJODE2010035191

Woodman, R.W., Sawyer, J.E., Griffin, R.W., 1993. Toward a theory of organizational creativity. Academy of management review 18, 293-321.

Wu, S.C., Fang, W., 2010. The effect of consumer-to-consumer interactions on idea generation in virtual brand community relationships. Technovation $\quad 30, \quad 570-581$. doi:10.1016/j.technovation.2010.07.005

Zhao, Z., Anand, J., Mitchell, W., 2004. Transferring collective knowledge: Teaching and learning in the Chinese auto industry. Strategic organization 2, 133-167. 